\title{
The Importance of the Validation of M/EEG With Current Biomarkers in Alzheimer's Disease
}

\begin{abstract}
Fernando Maestú 1,2,3* , Pablo Cuesta ${ }^{1,4}$, Omar Hasan ${ }^{5}$, Alberto Fernandéz ${ }^{1,6}$, Michael Funke ${ }^{3}$ and Paul E. Schulz ${ }^{5}$

${ }^{1}$ Laboratory of Cognitive and Computational Neuroscience, Center for Biomedical Technology, Universidad Complutense and Universidad Politécnica de Madrid, Madrid, Spain, ${ }^{2}$ Department of Experimental Psychology, Universidad Complutense de Madrid, Madrid, Spain, ${ }^{3}$ Magnetic Source Imaging Unit, Department of Pediatrics, McGovern Medical School, University of Texas Health Science Center, Houston, TX, United States, ${ }^{4}$ Electrical Engineering and Bioengineering Lab, Department of Industrial Engineering \& IUNE Universidad de La Laguna, Tenerife, Spain, ${ }^{5}$ McGovern Medical School University of Texas Health Science Center, Houston, TX, United States, ${ }^{6}$ Department of Legal Medicine, Psychiatry, and Pathology, Universidad Complutense de Madrid, Madrid, Spain
\end{abstract}

Current biomarkers used in research and in clinical practice in Alzheimer's Disease (AD) are the analysis of cerebral spinal fluid (CSF) to detect levels of $A \beta 42$ and phosphorylated-tau, amyloid and FDG-PET, and MRI volumetry. Some of these procedures are still invasive for patients or expensive. Electroencephalography (EEG) and Magnetoencephalography (MEG) are two non-invasive techniques able to detect the early synaptic dysfunction and track the course of the disease. However, in spite of its added value they are not part of the standard of care in clinical practice in dementia. In this

OPEN ACCESS

Edited by:

Camillo Porcaro,

Istituto di Scienze e Tecnologie della Cognizione (ISTC), Italy

Reviewed by:

Mario Tombini,

Campus Bio-Medico University, Italy Yuri Zillberter,

INSERM U1106 Institut de Neurosciences des Systèmes, France

${ }^{*}$ Correspondence:

Fernando Maestú

fernando.maestu@uth.tmc.edu;

fmaestuu@ucm.es

Received: 24 October 2018 Accepted: 15 January 2019 Published: 05 February 2019

Citation:

Maestú F, Cuesta P, Hasan O, Fernandéz A, Funke $M$ and Schulz PE (2019) The Importance of the Validation of M/EEG With Current Biomarkers in Alzheimer's Disease.

Front. Hum. Neurosci. 13:17.

doi: 10.3389/fnhum.2019.00017 paper we review what these neurophysiological techniques can add to the early diagnosis of $A D$, whether results in both modalities are related to each other or not, as well as the need of its validation against current biomarkers. We discuss their potential implications for the better understanding of the pathophysiological mechanisms of the disease as well as the need of performing simultaneous M/EEG recordings to better understand discrepancies between these two techniques. Finally, more studies are needed studying M/EEG with amyloid and Tau biomarkers.

\section{Keywords: functional connectivity, mild cognitive impairment, EEG, MEG, healthy aging, Alzheimer's disease}

\section{INTRODUCTION}

Alzheimer's disease (AD) is the major cause of dementia in the elderly (Qiu et al., 2009). It is characterized by the accumulation of amyloid beta $(A \beta)$ protein, the hyperphosphorylation of tau protein, and neuroinflammation, that are thought to lead to neuronal loss and synaptic dysfunction. Current biomarkers used in research and in clinical practice are the analysis of cerebral spinal fluid (CSF) to detect levels of A $\beta 42$ and phosphorylated-tau, amyloid and FDGPET, and MRI volumetry. Pathological changes associated with AD, such as amyloid deposition, start decades before the first clinical symptoms appear, and clinically-relevant functional loss may be irrecoverable once the disease process has progressed. As such, it is imperative to detect neuropathological changes, especially those at the synaptic level, as early in the development of the disease process as possible. While the increased amyloid burden can be detected in preclinical stages in subjects at risk of dementia (Dubois et al., 2016; Jack et al., 2017), hypometabolism, and cortical atrophy is typically not detected until the early dementia stages, such as prodromal 
dementia (Jack et al., 2013, 2017). Amyloid load has not been clearly associated with cognitive impairment, however, increased tau at CSF showed high correlation with cognitive deficit (Nelson et al., 2012; Vos et al., 2013). Amyloid PET and CSF are too invasive and expensive to use to screen large numbers of presymptomatic patients. Thus, a test is needed that can be used to screen large populations, demonstrated the onset of the neuropathology of the disease, that is easy to use and noninvasive, to be able to detect the initial stages of the disease and to track its course.

\section{ELECTROPHYSIOLOGICAL TECHNIQUES TO DETECT PRESYMPTOMATIC AD}

The analysis of human and animal brain tissues has shown that amyloid plaques may have a toxic effect on inhibitory terminals (Garcia-Marin et al., 2009) as well as for excitatory neurons (Pozueta et al., 2013; Wang et al., 2017). This phenomenon disrupts the normal balance between excitation and inhibition in neuronal activity, increasing neuronal excitability and damaging neural network function (Busche and Konnerth, 2016; Teipel et al., 2016; Sepulcre et al., 2017). Furthermore, hyperactivity of hippocampal neurons precedes amyloid plaque formation, suggesting that hyperactivity is one of the earliest dysfunctions in the pathophysiological cascade initiated by abnormal $A \beta$ accumulation (Busche and Konnerth, 2016).

Various forms of p-Tau also alter the normal network functioning. Tau deposition disrupts the axonal microtubule architecture (Taniguchi et al., 2001) and its deposits correlates with cognitive impairment (Nelson et al., 2012; Vos et al., 2013; Albert et al., 2018) and network dysfunction (Schultz et al., 2017). This progressive loss of synapse efficiency and quantity, disrupts inter- and intra-regional communication, leading to the proposal that $\mathrm{AD}$ is a disconnection syndrome (Hardy and Selkoe, 2002; Delbeuck et al., 2003).

These pathophysiological processes have direct consequences on neural transmission and therefore can be detected by neurophysiological techniques. Synaptic dysfunction and disruption of connectivity, then, can be studied with Magnetoencephalography (MEG) and Electroencephalography (EEG) (M/EEG). MEG records the magnetic fields induced by intracellular post-synaptic activity (Hari and Puce, 2017) and the EEG is a direct measure of neuronal field potentials that can be used to assess the organization of brain functional architecture in AD (Stam, 2010). It is true that while their temporal resolution is high their ability to localize brain activity from deep sources is limited. However, the time-frequency resolution allows for detecting brain oscillatory activity which contains the "neural code" for the local and long-range transmission of information. MEG is reference free avoiding the need of a reference to close the electrical current needed in EEG which could modify the phase of the signals detected in each electrode. If synaptic dysfunction and network impairment start decades before the main cognitive symptoms appear (Jansen et al., 2015), they could be detected early in time by M/EEG. Their non-invasive nature allows the performance of as many recordings as needed in each subject, contrary to other neuroimaging modalities. This allows for detecting changes associated with healthy aging (Fernández et al., 2012; Porcaro et al., 2019), tracking the course of the disease and the assessment of pharmacological and non-pharmacological interventions.

\section{THE ROLE OF ELECTROPHYSIOLOGICAL TECHNIQUES IN DETECTING ALZHEIMER DISEASE}

Until now, the use of M/EEG in dementia has had a minor role. In fact, its use in the elderly population has been limited to the discard of epileptogenic activity or the detection of generalized slow wave activity. In the last two decades great advances in the analysis of the information contained in the M/EEG temporal series have revealed fundamental pathological mechanisms that could constitute new signs for early diagnosis and prognosis in the AD process.

While the advanced stages of $\mathrm{AD}$ may be associated with functional disconnection (Stam et al., 2009), earlier stages may be apparent in terms of communication disruption such as hypersynchronization as revealed by MEG (Maestú et al., 2008; Bajo et al., 2010; Buldú et al., 2011). Indeed, MEG studies of patients with Mild Cognitive Impairment (MCI) found alterations in network organization across the cortex preceding clinical dementia (López et al., 2014; Maestú et al., 2015). Findings in resting state activity show a dual pattern of increasing and decreasing functional connectivity over prefrontal and posterior regions, respectively, mainly in the alpha band (Maestú et al., 2008; López-Sanz et al., 2017a). To assess the clinical value of MEG and explore in more detail whether hypersynchronization could be a hallmark of network disruption, an international consortium of MEG laboratories from five countries and three different continents was established (Magnetoencephalography International Consortium for the Study of AD; MAGIC-AD). This study evaluated MEG functional networks as a biomarker at the individual level in a blind study. A machine learning approach was used to classify MCI and healthy controls providing an accurate classification, over 80\% (Maestú et al., 2015). Again, increased synchronization between anterior and posterior regions provided the better classification rate.

A common factor discovered in all these studies was an increased synchronization between prefrontal and posterior regions, reflecting an imbalance between excitation/inhibition, leading to spurious synchrony (see Table 1). In fact, higher synchronization did not provide better cognitive performance. Hyposynchronization in posterior regions (López-Sanz et al., 2017a) was also found, indicating a dual pattern, which could reflect two different mechanism: first hypersynchrony due to the loss of E/I balance (Busche and Konnerth, 2016) and then hyposynchrony reflecting degeneration (López-Sanz et al., 2017a).

An additional step was applying the principles of graph theory to MEG analysis to test whether this disruption in communication affected the architecture of the functional networks in early stages. López-Sanz et al. (2017b), found that 
TABLE 1 | Studies of M/EEG in preclinical $A D$ and MCl.

\begin{tabular}{|c|c|c|c|c|}
\hline References & Comparison & Sample size & Methodology & Result \\
\hline Babiloni et al., 2018 & $\mathrm{MCl}$ vs. CN & $75 \mathrm{MCl}, 75 \mathrm{CN}$ & $\begin{array}{l}\text { Sources, Resting, EEG, } \\
\text { FC }\end{array}$ & Widespread decreased alpha FC \\
\hline Babiloni et al., 2016 & AD vs. CN & $19 \mathrm{AD}, 40 \mathrm{CN}$ & $\begin{array}{l}\text { Sources, Resting, EEG, } \\
\text { Activity }\end{array}$ & $\begin{array}{l}\text { Higher delta and lower low frequency alpha activities. } \\
\text { Association between hypometabolism and delta activity }\end{array}$ \\
\hline Bajo et al., 2010 & $\mathrm{MCl}$ vs. $\mathrm{CN}$ & $22 \mathrm{MCl}, 19 \mathrm{CN}$ & Sensors, Task, MEG, FC & $\begin{array}{l}\text { Increased long distance interhemispheric FC \& } \\
\text { decreased anteroposterior FC }\end{array}$ \\
\hline Buldú et al., 2011 & $\mathrm{MCl}$ vs. CN & $19 \mathrm{MCl}, 19 \mathrm{CN}$ & $\begin{array}{l}\text { Sensors, Task, MEG, } \\
\text { Graphs }\end{array}$ & Increased network strength and outreach \\
\hline Canuet et al., 2015 & $\mathrm{MCl}$ & $4 \mathrm{pMCl}, 8 \mathrm{sMCl}$ & $\begin{array}{l}\text { Sources, Resting, MEG, } \\
\text { FC }\end{array}$ & $\begin{array}{l}\text { Dual increased/decreased FC pattern affecting limbic } \\
\text { structures. Decreased FC associated with impaired } \\
\text { axonal integrity }\end{array}$ \\
\hline Cuesta et al., 2015 & $\mathrm{MCl}$ vs. CN f(ApoE) & $\begin{array}{l}20 \mathrm{MCl} \varepsilon \varepsilon 4,16 \mathrm{MCl} 1 \varepsilon 4 \\
8 \mathrm{CN} 1 \varepsilon 4,19 \mathrm{CNO} \varepsilon 4\end{array}$ & $\begin{array}{l}\text { Sources, Resting, MEG, } \\
\text { FC }\end{array}$ & $\begin{array}{l}\text { Decreased alpha and beta hippocampal and IPL FC in } \\
\mathrm{MCl} \text {. Decreased delta FC in ApoE34. Dual } \\
\text { increased/decreased FC pattern affecting } \\
\text { frontal/temporal regions }\end{array}$ \\
\hline Dubois et al., 2018 & SCD & 88 SCDp, 230 SCDn & $\begin{array}{l}\text { Sources, Resting, EEG, } \\
\text { Power }\end{array}$ & $\begin{array}{l}\text { Increase in alpha power over time in prefrontal areas in } \\
A \beta \text { positive subjects at baseline }\end{array}$ \\
\hline Fernández et al., 2002 & AD vs. CN & $15 \mathrm{AD}, 19 \mathrm{CN}$ & $\begin{array}{l}\text { Sources, Resting, MEG, } \\
\text { Power }\end{array}$ & Increased bilateral temporoparietal delta and theta power \\
\hline $\begin{array}{l}\text { Gonzalez-Escamilla } \\
\text { et al., } 2014\end{array}$ & $\mathrm{MCl}$ vs. CN & $29 \mathrm{MCl}, 26 \mathrm{CN}$ & $\begin{array}{l}\text { Sources, Resting, EEG, } \\
\text { FC }\end{array}$ & Decreased frontotemporal and parietal alpha FC \\
\hline Hata et al., 2017 & $A D$ & $14 \mathrm{AD}$ & $\begin{array}{l}\text { Sources, Resting, EEG, } \\
\text { FC }\end{array}$ & $\begin{array}{l}\text { Tau negative correlated with FC left frontal eye field and } \\
\text { the right auditory }\end{array}$ \\
\hline Jelic et al., 1997 & $\mathrm{MCl}$ f(ApoE) vs. CN & $\begin{array}{l}17 \mathrm{MCl} \varepsilon \varepsilon 4,14 \mathrm{MCl} 1 \varepsilon 4 \\
10 \mathrm{MCl} 2 \varepsilon 4,18 \mathrm{CN}\end{array}$ & $\begin{array}{l}\text { Sensors, Resting, EEG, } \\
\text { power, and FC }\end{array}$ & $\begin{array}{l}\text { APOE } \varepsilon 4 \text { seems to be associated with selective } \\
\text { decreases in FC }\end{array}$ \\
\hline Jelic et al., 1998 & AD continuum & $14 \mathrm{AD}, 12 \mathrm{MCl}, 14 \mathrm{CN}$ & $\begin{array}{l}\text { Sensors, Resting, EEG, } \\
\text { Power }\end{array}$ & Association between tau and the $\mathrm{a} / \mathrm{d}$ power ratio \\
\hline Koenig et al., 2005 & AD continuum f(GDS) & $\begin{array}{l}211 \mathrm{AD}, 92 \mathrm{MCl}, 70 \\
\text { SCD, } 46 \mathrm{CN}\end{array}$ & $\begin{array}{l}\text { Sensors, Resting, EEG, } \\
\text { FC }\end{array}$ & $\begin{array}{l}\text { Decreased FC in Alpha, Beta, and Gamma frequency } \\
\text { bands, and increased delta FC }\end{array}$ \\
\hline Kramberger et al., 2013 & AD vs. MCl vs. SCD & $\begin{array}{l}131 \mathrm{AD}, 285 \mathrm{MCl}, 310 \\
\text { SCD }\end{array}$ & $\begin{array}{l}\text { Sensors, Resting, EEG, } \\
\text { Activity }\end{array}$ & $\begin{array}{l}\text { Slower activity correlated with lower } A \beta 42 / \text { ptau ratio and } \\
\text { higher total tau. }\end{array}$ \\
\hline López-Sanz et al., 2016 & $\mathrm{MCl}$ vs. SCD vs. CN & $51 \mathrm{MCl}, 41 \mathrm{SCD}, 39 \mathrm{CN}$ & $\begin{array}{l}\text { Sources, Resting, MEG, } \\
\text { Power }\end{array}$ & $\begin{array}{l}\text { Decreased alpha power. } \mathrm{MCl} \text { showed slowing in their } \\
\text { alpha peak }\end{array}$ \\
\hline $\begin{array}{l}\text { López-Sanz et al., } \\
2017 \text { a }\end{array}$ & $\mathrm{MCl}$ vs. SCD vs. CN & $51 \mathrm{MCl}, 41 \mathrm{SCD}, 39 \mathrm{CN}$ & $\begin{array}{l}\text { Sources, Resting, MEG, } \\
\text { FC }\end{array}$ & $\begin{array}{l}\text { Increased alpha anterior FC and decreased posterior } \\
\text { alpha FC }\end{array}$ \\
\hline $\begin{array}{l}\text { López-Sanz et al., } \\
\text { 2017b }\end{array}$ & $\mathrm{MCl}$ vs. SCD vs. CN & $69 \mathrm{MCl}, 55 \mathrm{SCD}, 63 \mathrm{CN}$ & $\begin{array}{l}\text { Sources, Resting, MEG, } \\
\text { Graphs }\end{array}$ & $\begin{array}{l}\text { SCD showed an intermediate degree (between } \mathrm{MCl} \text { and } \\
\mathrm{CN} \text { ) of network disruption in multiple parameters }\end{array}$ \\
\hline Maestú et al., 2008 & $\mathrm{MCl}$ vs. CN & $15 \mathrm{MCl}, 20 \mathrm{CN}$ & $\begin{array}{l}\text { Sources, Task, MEG, } \\
\text { Activation }\end{array}$ & Bilateral higher activity in the ventral pathway \\
\hline Maestú et al., 2015 & $\mathrm{MCl}$ vs. CN & $102 \mathrm{MCl}, 82 \mathrm{CN}$ & $\begin{array}{l}\text { Sensors, Resting, MEG, } \\
\text { FC }\end{array}$ & $\begin{array}{l}\text { Enhanced fronto-parietal and interhemispheric } \\
\text { broadband FC }\end{array}$ \\
\hline Moretti et al., 2017 & $\mathrm{MCl}$ & $23 \mathrm{MCl}$ & $\begin{array}{l}\text { Sensors, Resting, EEG, } \\
\text { Power }\end{array}$ & $\begin{array}{l}\text { Subjects with increased } \mathrm{Ha} / \mathrm{La} \text { showed hypometabolism } \\
\text { and higher ratio of conversion }\end{array}$ \\
\hline Nakamura et al., 2017 & CNp vs. CN & $13 \mathrm{CNp}, 32 \mathrm{CN}$ & $\begin{array}{l}\text { Sources, Resting, MEG, } \\
\text { FC }\end{array}$ & $\begin{array}{l}\text { Decreased local FC in Pcu. Increased FC between Pcu } \\
\text { and both IPL }\end{array}$ \\
\hline Nakamura et al., 2018 & $\mathrm{MCl}$ vs. CNp vs. CN & $\begin{array}{l}28 \mathrm{MCl}, 11 \mathrm{MClnoAD} \\
13 \mathrm{CNp}, 17 \mathrm{CN}\end{array}$ & $\begin{array}{l}\text { Sources, Resting, MEG, } \\
\text { Power }\end{array}$ & $\begin{array}{l}\text { Increased frontal alpha power in } \mathrm{MCl} \text { and } \mathrm{CNp} \text {. } \\
\text { Increased frontal delta power in } \mathrm{MCl} \text { vs. CNp. Global } \\
\text { increased theta power in } \mathrm{MCl}\end{array}$ \\
\hline Smailovic et al., 2018 & AD vs. MCl vs. SCD & $\begin{array}{l}197 \mathrm{AD}, 230 \mathrm{MCl}, 210 \\
\text { SCD }\end{array}$ & $\begin{array}{l}\text { Sensors, Resting, EEG, } \\
\text { power, and FC }\end{array}$ & $\begin{array}{l}\text { A } \beta 42 \text { correlated inversely with theta and delta power. Tau } \\
\text { correlated negatively with alpha power. Alpha and beta } \\
\text { FC correlated inversely with increased pathology }\end{array}$ \\
\hline Stomrud et al., 2010 & $\mathrm{CN}$ & $33 \mathrm{CN}$ & $\begin{array}{l}\text { Sensors, Resting, EEG, } \\
\text { Power }\end{array}$ & $\begin{array}{l}\text { Association between theta power and tau CSF } \\
\text { measurements }\end{array}$ \\
\hline Teipel et al., 2018 & SCD & 63 SCDp, 255 SCDn & $\begin{array}{l}\text { Sensors, Resting, EEG, } \\
\text { FC }\end{array}$ & $\begin{array}{l}\text { Non global significant results. A } \beta p \text { participants showed } \\
\text { enhanced alpha FC and diminished beta FC }\end{array}$ \\
\hline
\end{tabular}

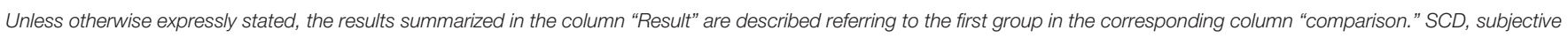

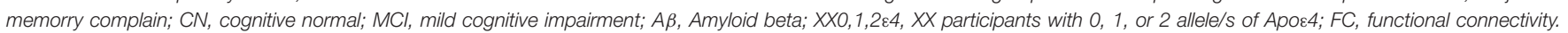

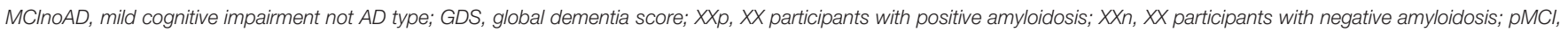
progressive mild cognitive impairment; sMCl, stable mild cognitive impairment; Ha/La, high alpha/low alpha ratio; a/d, alpha/delta ratio; PCu, precuneus; IPL, inferior parietal lobe. 
the MCI patients showed a decreased small-worldness, clustering, and transitivity as well as increased modularity in theta and beta bands. Another group with Subjective Cognitive Decline (SCD) showed similar but smaller changes in clustering and transitivity, while exhibiting alterations in the alpha band in the opposite direction of that shown by MCI for modularity and transitivity. Clustering was disrupted as well in MCI and SCD. Additionally, it was observed that there is an increase in modular partition variability in both SCD and MCI in theta and beta bands. All these findings reflect a progressive loss of network architecture that is associated with worsening of cognitive symptoms.

One important issue that needed further research was the reliability of the results of the functional networks. This was necessary to be able to track different stages of $\mathrm{AD}$ continuum and to test the efficacy of pharmacological and non-pharmacological interventions. Thus, regarding the reproducibility of the functional network results, it was performed a study in which subjects underwent three MEG scans in three separate days and different functional connectivity metrics were assessed in the source space. The intraclasscorrelation was very high for phase synchrony metrics, in different brain networks such as the motor and the somatosensory cortex, and the default mode network (Garcés et al., 2016a).

While MEG studies have found a dual pattern of hyper and hyposynchrony, a more consistent finding in EEG has been a reduced alpha to beta coherence (Jelic et al., 1997; Jeong, 2004; Fonseca et al., 2013). Gonzalez-Escamilla et al. (2014) showed a reduction of alpha interhemispheric coupling in MCI patients compared to controls, with this effect being greater in APOE4 carriers. Recently, Babiloni et al. (2018), using an advanced technique for functional connectivity analysis, showed intra and interhemispheric reduction of alpha band network functioning in $\mathrm{AD}$ patients that were able to distinguish them from healthy elderly subjects and Parkinson Disease patients. In early stages, such as MCI, patients again showed a decrease of alpha functional connectivity in several brain regions (Babiloni et al., 2018). Combining a small world metric and APOE4 positivity, Vecchio et al. (2018) showed a 91.7\% accuracy for correct classification of a large cohort MCI patients who did or did not convert to AD. Finally, Dauwan et al. (2016) using an effective connectivity metric showed that the common posterior-to-anterior pattern of directed connectivity in controls is reduced in dementia with Lewy bodies patients in the alpha band, and in $\mathrm{AD}$ patients in the beta band.

In all these EEG studies, the most prominent profile was a decreased functional connectivity with consequences on network architecture. This discrepancy with MEG findings, i.e., the dual pattern of hypo and hypersynchrony, should be further investigated and evaluated as to why hypersynchrony is not being detected regularly in EEG studies. This could be due to differences in the population tested (more advanced cognitive impairment in EEG studies than in MEG) or because of technical issues (different source reconstruction methods, metrics of functional connectivity, or reference in EEG). Simultaneous $\mathrm{M} / \mathrm{EEG}$ recordings in healthy elders and in SCD/MCI/AD subjects are needed to evaluate similarities and differences between both techniques in the same sample.

\section{M/EEG AS A BIOMARKER FOR CONVERSION FROM MCI TO DEMENTIA}

A crucial factor for considering $\mathrm{M} / \mathrm{EEG}$ as a biomarker for $\mathrm{AD}$ is its capability to predict conversion across the different stages of the disease (preclinical-prodromal-dementia). There are very few longitudinal studies and all focused in the conversion from MCI to dementia (see Table 2). In two longitudinal studies (2 years of follow-up) with a similar sample, those MCI patients who developed dementia showed higher alpha band synchronization than those who remained stable (Bajo et al., 2012; López et al., 2014). The higher the synchronization between the anterior cingulate cortex and the posterior cortical regions, the higher the likelihood for developing dementia (López et al., 2014). Furthermore, patients that showed high levels of $\mathrm{p}$-tau in the CSF and later on developed dementia showed again an increased synchronization between the medial temporal lobe and the anterior cingulate cortex in the beta frequency band (Canuet et al., 2015).

In EEG, Jelic et al. (2000) did not find differences between MCI converters and stable at the time they all were MCI, but a subsequent evaluation showed that converters increased their theta relative power and decreased beta in the temporal lobe. Subsequent studies with EEG were consistent in finding increased delta power over temporal regions in MCI converters compared with non-converters (Rossini et al., 2006). Alpha differences were found as well, with a reduced posterior power density (Luckhaus et al., 2008). However, a discrepant finding was found by Moretti et al. (2011) where converters showed an increased alpha3/alpha2 ratio. Finally, in healthy subjects who were CSF/amyloid (+) with subjective memory complaints, higher delta and theta power predicted conversion to cognitive impairment, however, no association was found with tau protein (Gouw et al., 2017). Regarding functional connectivity, Rossini et al. (2006) found increased fronto-parietal coherence in agreement with the increased functional connectivity values found in converters in MEG studies (López et al., 2014).

An interesting approach was the one proposed by Poil et al. (2013) in which they combine the information from multiple EEG biomarkers into a diagnostic classification index to improve the accuracy of predicting conversion from MCI to AD. By integrating six EEG biomarkers [Amplitude correlations with $\mathrm{Cz}$ in Beta $(13-30 \mathrm{~Hz})$; bandwidth of subject-specific Beta frequency; peak width of dominant beta peak; range of amplitude values in Beta $(13-30 \mathrm{~Hz})$; ratio between theta and alpha power; and alpha relative power normalized with $1-45 \mathrm{~Hz}$ broadband] into a diagnostic index the prediction achieved a sensitivity of $88 \%$ and specificity of $82 \%$, compared with a sensitivity of $64 \%$, and specificity of $62 \%$ of the best individual biomarker.

\section{THE RELATIONSHIP BETWEEN FINDINGS ON MEG AND EEG IN DEMENTIA}

The findings discussed thus far suggest an important potential for using the hyper/hyposynchronization phenomena detected with MEG as a non-invasive diagnostic biomarker. However, 
TABLE 2 | Studies of M/EEG on progression along AD continuum.

\begin{tabular}{|c|c|c|c|c|}
\hline References & Comparison & Sample size & Methodology & Result \\
\hline Bajo et al., 2012 & pMCl vs. sMCl & $5 \mathrm{pMCl}, 14 \mathrm{sMCl}$ & Sensors, Task, MEG, FC & Increased parieto-occipital and frontal FC \\
\hline Gouw et al., 2017 & $\begin{array}{l}\text { pSCD vs. sSCD; pMCl } \\
\text { vs. sMCl }\end{array}$ & $\begin{array}{l}25 \mathrm{pSCD}, 38 \mathrm{sSCD}, 83 \\
\mathrm{pMCl}, 59 \mathrm{sMCl}\end{array}$ & $\begin{array}{l}\text { Sensors, Resting, EEG, } \\
\text { Power }\end{array}$ & $\begin{array}{l}\text { pSCD showed higher delta and theta power and lower } \\
\text { alpha power and peak frequency }\end{array}$ \\
\hline Jelic et al., 2000 & $\begin{array}{l}\text { AD vs. pMCl vs. sMCl } \\
\text { vs. } \mathrm{CN}\end{array}$ & $\begin{array}{l}15 \mathrm{AD}, 14 \mathrm{pMCl}, 13 \\
\mathrm{sMCl}, 16 \mathrm{CN}\end{array}$ & $\begin{array}{l}\text { Sensors, Resting, EEG, } \\
\text { Power }\end{array}$ & $\begin{array}{l}\mathrm{MCl} \text { groups showed lower theta power than } \mathrm{AD} . \mathrm{pMCl} \\
\text { showed higher theta and lower beta }\end{array}$ \\
\hline Jovicich et al., 2018 & $\mathrm{MCl}$ vs. MClnoAD & $81 \mathrm{MCl}, 63 \mathrm{MClnoAD}$ & $\begin{array}{l}\text { Sources, Resting and } \\
\text { Task, EEG, Activity }\end{array}$ & $\begin{array}{l}\text { Increased delta and theta and decreased low frequency } \\
\text { alpha activities. Reduced parietal/posterior task activity }\end{array}$ \\
\hline López et al., 2014 & pMCl vs. sMCl & $19 \mathrm{pMCl}, 30 \mathrm{sMCl}$ & $\begin{array}{l}\text { Sources, Resting, MEG, } \\
\text { FC }\end{array}$ & $\begin{array}{l}\text { Increased alpha FC between right anterior cingulate and } \\
\text { temporo-occipital regions }\end{array}$ \\
\hline Luckhaus et al., 2008 & pMCl vs. sMCl vs. AD & $44 \mathrm{AD}, 88 \mathrm{MCl}$ & $\begin{array}{l}\text { Sensors, Resting, EEG, } \\
\text { Power }\end{array}$ & $\begin{array}{l}\text { Decreased alpha power over posterior regions. } 22 \% \text { of } \\
\mathrm{MCl} \text { progressed to dementia }\end{array}$ \\
\hline Moretti et al., 2011 & pMCl vs. sMCl & $\begin{array}{l}18 \mathrm{pMCl}, 14 \text { DnoAD, } 44 \\
\mathrm{sMCl}\end{array}$ & $\begin{array}{l}\text { Sensors, Resting, EEG, } \\
\text { Power }\end{array}$ & $\begin{array}{l}\text { Increased t/g ratio associated with dementia; increased } \\
\text { a3/a2 ratio associated with } A D\end{array}$ \\
\hline Poil et al., 2013 & pMCl vs. sMCl & $25 \mathrm{pMCl}, 61 \mathrm{sMCl}$ & $\begin{array}{l}\text { Sensors, Resting, EEG, } \\
\text { Power }\end{array}$ & $\begin{array}{l}\text { Combination of EEG signatures in the beta band } \\
\text { predicted conversion to } A D\end{array}$ \\
\hline Rossini et al., 2006 & pMCl vs. sMCl & $24 \mathrm{pMCl}, 45 \mathrm{sMCl}$ & $\begin{array}{l}\text { Sources, Resting, EEG, } \\
\text { FC }\end{array}$ & Increased FC in several frequency bands \\
\hline Vecchio et al., 2018 & pMCl vs. sMCl & $71 \mathrm{pMCl}, 74 \mathrm{sMCl}$ & $\begin{array}{l}\text { Sources, Resting, EEG, } \\
\text { Graphs }\end{array}$ & $\mathrm{AD}$ like small worldness pattern in $\mathrm{pMCl}$ \\
\hline
\end{tabular}

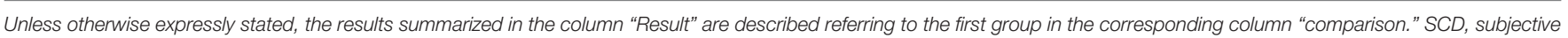

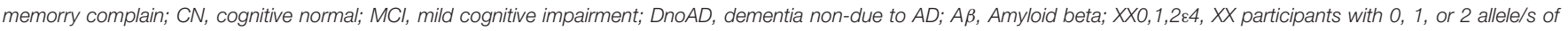

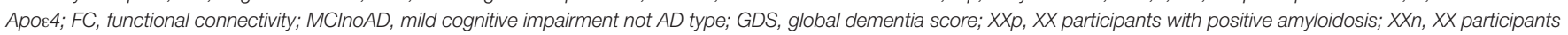

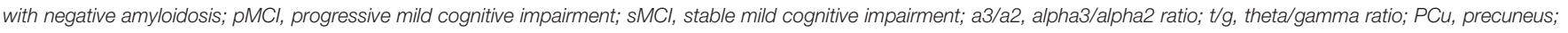
IPL, inferior parietal lobe; $P S C D$, progressive subjective memory complain; $s S C D$, stable progressive memory complain.

the use of MEG world-wide is still not as common as MRI or EEG, suggesting that it would be important to demonstrate how EEG can be used to detect the findings found on MEG. M/EEG data compatibility in epilepsy has already been demonstrated (Aydin et al., 2015; Hunold et al., 2016), but there are no papers indicating how functional network results in $\mathrm{AD}$ are compatible between MEG and EEG. This needs simultaneous recordings in healthy elderly subjects and in patients at different stages of the disease. Lacking these simultaneous recordings, we have to refer to the similarities between MEG and EEG on the previous findings reviewed above. Their correlation is fairly great in the majority of the studies, however, some discrepancies still exist, especially showing reduced functional connectivity in early stages of the disease in EEG (Babiloni, 2018), instead of a dual pattern dominated by hypersynchronization as showed in MEG studies (Jelic et al., 1997; Jeong, 2004; Koenig et al., 2005; Fonseca et al., 2013; López-Sanz et al., 2017a; Nakamura et al., 2017).

\section{M/EEG AND CURRENT BIOMARKERS OF AD}

It would be important for M/EEG to add additional information regarding the pathogenesis, diagnosis and prognosis of dementia, as well as to serve as a tool for tracking the course of the disease to evaluate the consequences of novel therapeutic interventions. The first step in this would be to show how their findings correlate with current biomarkers, such as cerebrospinal fluid (CSF) or PET measures of amyloid-beta.
There are still very few papers evaluating this compatibility. Recently, Nakamura et al. (2017) showed in a MEG study how deposits of amyloid protein alter network organizations in healthy elderly compared to amyloid negative elderly subjects. Functional connectivity was especially disrupted in regions with high amyloid deposits such as the inferior parietal lobe and the precuneus. In fact, there was a correlation between the high amyloid deposition and brain synchrony in those two regions. The importance of these results is that this network impairment preceded FDG-hypometabolism or brain atrophy. Therefore, hypersynchrony was detected in very early preclinical stages. In a subsequent analysis of the same data, they showed how local networks were also altered in association with amyloid depositions. Thus, alpha power was increased in prefrontal regions in correlation with high amyloid deposition in healthy elderly subjects. This time, brain magnetic activity was also recorded in MCI patients and showed increased alpha power over prefrontal regions where high amyloid deposition was detected (Nakamura et al., 2018).

In this review, we found just one paper attempting to correlate levels of $\mathrm{p}$-Tau in the CSF with resting state MEG activity in patients with MCI. That study found a positive correlation between the levels of the $\mathrm{p}$-tau protein and the functional connectivity values between medial temporal lobe and anterior cingulate cortex in subjects with prodromal AD (Canuet et al., 2015). This finding agrees with the tau neuropathology network-model, as described by Braak and Braak, and with recent ideas of "transneuronal neurodegeneration" (Fornito et al., 2015). The potential network alterations driven by transneuronal degeneration shape a unique framework to assess the cascade 
of neuropathological changes underlying the progression of $\mathrm{AD}$ using M/EEG-tau-PET. In this study, the authors showed a decrease in phase synchronization between the motor cortex and posterior cingulate cortex as well as between orbitofrontal region and temporo-occipital cortex. This decreased synchronization could indicate a functional disconnection in these MCI subjects. A reduction in posterior cingulate functional connectivity mediated by p-tau was also associated with impaired axonal integrity of the hippocampal cingulum as evaluated by diffusion tensor imaging, which could be understood as a functional diaschisis (Canuet et al., 2015). This supports the notion that the disruption of anatomical networks influences brain organization at the functional level (Kuczynski et al., 2010), perhaps contributing to the clinical manifestations of MCI (Pineda-Pardo et al., 2014).

Another important comparison necessary to better understand the role of MEG in dementia was to compare MEG results with genetic profiles of elderly subjects. One study investigated the modulation of functional networks in participants carrying the APOE4 allele, comparing healthy elders and MCI patients who did or did not carry the APOE4 allele. Healthy elderly carriers showed an increased synchronization between anterior and posterior regions while MCI carriers showed lower synchronization. This suggests that being a carrier of the $\varepsilon 4$ allele increases the risk for developing dementia and as well increases the probability for showing hypersynchrony in key brain regions. MCI carriers showed higher network disruption with a decrease in functional connectivity in the same regions where healthy elderly carriers showed increased synchrony values (Cuesta et al., 2015).

All these studies indicate that hypersynchrony appears in preclinical stages (healthy elders with high amyloid deposition or carriers of APOE4 and in SCD subjects) and in later stages hyposynchrony is a sign of neurodegeneration. Thus, an early unbalance between excitation and inhibition mechanisms could responsible for excessive excitatory activity that may lead to neuronal impairment (Busche and Konnerth, 2016).

Regarding EEG and biomarkers, there are still few published papers. Comparing EEG and glucose metabolism by FDG-PET (Moretti et al., 2017), found hypometabolism in MCI patients with higher high-alpha/low-alpha power ratio. A compatible result was found by Babiloni et al. (2016) where higher activity of delta sources and lower activity of low-alpha sources was found in cortical regions with lower glucose metabolism. In another study, however, no significant relationship between glucose consumption and cortical alpha-phase coupling was found either in MCI ApoE4 carriers or non-carriers (Gonzalez-Escamilla et al., 2014).

Regarding amyloid-PET, two related studies did not find differences between amyloid-PET $(+)$ and $(-)$ individuals (Dubois et al., 2018; Teipel et al., 2018). Analyzing just the amyloid $(+)$ subjects separately, they found an increased functional connectivity in regions with high amyloid deposition; however, the correlations were not statistically significant after correction for multiple comparisons (Teipel et al., 2018). Taking blood-amyloid samples, Gonzalez-Escamilla et al. (2014) found that elevated levels of $\mathrm{A} \beta 1-42$ correlated with decreased parietooccipital functional connectivity in healthy subjects, but not in amnestic MCI subjects.

Jelic et al. (1998) were the first comparing CSF markers with EEG, finding a positive correlation between CSF tau levels and the alpha/delta power ratio in $\mathrm{AD}$ patients. Hata and coworkers (Hata et al., 2017) found a negative correlation between $A \beta 42$ concentration and theta current source density in the right temporal region. Additionally, when they assessed total tau concentration, this parameter was negatively correlated with the lagged phase synchronization between the left frontal eye field and the right auditory area in the alpha band in patients with AD. Thus, the higher total tau the less functional connectivity in the alpha band. The increased local theta (associated with lower amyloid in CSF) and the reduced alpha network (associated with higher total tau), then, were indicators of functional impairment. These results were compatible with a previous EEG study where the combined ratio of the phosphorylated tau and $A \beta 42$ showed a positive correlation with theta power in the right posterior electrodes (Stomrud et al., 2010; Kramberger et al., 2013). A recent EEG paper, showed increased resting state delta and theta rhythms and decreased low-frequency alpha $(8-10.5 \mathrm{~Hz})$ in MCI with positive biomarkers in the CSF (Jovicich et al., 2018). Similar findings were found by another independent study where lower $A \beta 42$ levels and high p-tau were associated with high delta/theta and low alpha/beta power respectively, while global field synchronization was decreased in alpha and beta (Smailovic et al., 2018).

Considering all these EEG studies, there seem to be inconsistencies between amyloid-PET and CSF studies. However, the low number of studies published could increase variability of the results due to differences in methodologies employed in diagnosis and data analysis. EEG/CSF studies appear to provide a consistent result, i.e., an increased slow activity power in posterior regions correlates with pathology at different stages of the disease. These results are consistent with MEG studies (Fernández et al., 2002; Nakamura et al., 2018). However, EEG/MEG tends to also show reductions in alpha band power (Garcés et al., 2013; Babiloni et al., 2014; López-Sanz et al., 2016), and diminished complexity in the electrophysiological signals (Fernández et al., 2010; Bruña et al., 2012; Smits et al., 2016).

Functional connectivity findings with EEG and MEG in correlation with CSF are very compatible. A dual pattern of hyper- and hypoconnectivity associated with $\mathrm{A} \beta 42$ and tau were found in the two studies available. However, M/EEG and amyloid-PET studies are clearly incongruent as in MEG studies there are robust differences between amyloid $(+)$ and $(-)$ healthy elderly subjects (Nakamura et al., 2017, 2018).

\section{DISCUSSION}

M/EEG has shown differential profiles of functional connections between healthy elders and patients at different stages of the $\mathrm{AD}$ continuum. These profiles seem to correlate with cognitive scores and the clinical course of the disease, being able to 
predict which of the SCD and MCI patients will convert to dementia.

Very few studies have tested for correlations with current biomarkers. The few studies that have been done show a correlation of MEG with both amyloid-PET and CSF values and EEG with CSF. There is an association with the genetic risk factor most frequently associated with $\mathrm{AD}$, i.e., being a carrier of an APOE4 allele. This correlation with current biomarkers was an important test for M/EEG to: (1) understand the basis of the hyper and hyposynchrony phenomenon and power reduction, and (2) to make possible its use in the clinical scenario. However, some discrepant findings between MEG and EEG indicate the need for a study where biomarkers would be acquired in the same sample of patients where simultaneous M/EEG recordings were being performed. A study testing whether hypersynchronization in the alpha band can also be consistently found in EEG in subjects with positive biomarkers at early stages is still needed. Hypersynchronization in the alpha band found in MEG at specific locations can also be tested and transferred to EEG in the context of a simultaneous recording, using the same metric for signal analysis.

Functional Magnetic Resonance Imaging (fMRI) can as well provide valuable information about the organization of brain networks (Bullmore and Bassett, 2011). In fact, multimodal studies with the same subjects have shown strong similarities between fMRI and MEG brain network topologies in alpha and beta frequency bands (Garcés et al., 2016b). fMRI has shown a disruption of brain network organization at different stages of the disease, essentially indicating a progressive disruption of the default mode network, both at the network level (Lim et al., 2014; Jones et al., 2015) and at the local level (Jovicich et al., 2018); being hub regions primarily impaired (Drzezga et al., 2011; Crossley et al., 2014). Furthermore, patients that convert from $\mathrm{MCI}$ to $\mathrm{AD}$ showed entorhinal/hippocampal hypoconnectivity in comparison to those that did not covert (Delli Pizzi et al., 2019). Interestingly, MCI patients who did not convert to $\mathrm{AD}$ or did not show CSF signs of disease showed hyperconnectivity between hippocampal/entorhinal with neocortical/subcortical regions (Delli Pizzi et al., 2019). These results are essentially in agreement with those found with electrophysiological techniques in certain frequency bands such as alpha and beta. Consequently, it is of interest to consider an integrative approach of the different potential biomarkers

\section{REFERENCES}

Albert, M., Zhu, Y., Moghekar, A., Mori, S., Miller, M. I., Soldan, A., et al. (2018). Predicting progression from normal cognition to mild cognitive impairment for individuals at 5 years. Brain 141, 877-87. doi: 10.1093/brain/ awx365

Aydin, Ü., Vorwerk, J., Dümpelmann, M., Küpper, P., Kugel, H., Heers, M., et al. (2015). Combined EEG/MEG can outperform single modality EEG or MEG source reconstruction in presurgical epilepsy diagnosis. PLoS ONE 10:e0118753. doi: 10.1371/journal.pone.0118753

Babiloni, C., Del Percio, C., Caroli, A., Salvatore, E., Nicolai, E., Marzano, N., et al. (2016). Cortical sources of resting state Eeg rhythms are related to provided by M/EEG with those provided by fMRI. Poil et al. (2013), showed how the integration between six EEG biomarkers improve the classification between converters and non-converters. This approach could be as well be very beneficial for MEG biomarkers and for combining EEG and MEG findings to achieve a global neurophysiological index. By using deep learning approaches this combination of potential biomarkers could go beyond electrophysiological biomarkers including genetics, fMRI and MRI modalities as well as neuropsychological tests and life style factors. Compatibility is always subjected to non-redundant information. While M/EEG and fMRI data are compatible at certain frequency bands, there are others frequencies which seem to provide additional information. Conversely, fMRI provide information from deep brain regions where M/EEG sensors are nowadays not capable to achieve good signal to noise ratios. Therefore, these two views of brain functional activity are compatible as they provide complementary information (see Jovicich et al., 2018). As commented above, the use of deep learning approaches combining different sources of information could overcome the limitations of a single modality improving our knowledge of the structural and functional basis of $\mathrm{AD}$.

Four main conclusions come from this review: (1) more studies are needed correlating M/EEG with current biomarkers to validate these neurophysiological techniques for a regular use in the clinical scenario; (2) multicenter, blind studies with biomarkers will provide reliability and accuracy values for classification; (3) include other sources of information such as genetics, PET, MRI, life style factors, and neuropsychological scores to achieve a more global view of the disease; and, (4) simultaneous M/EEG recordings in elderly subjects would test the compatibility of the functional connectivity results between these two techniques.

\section{AUTHOR CONTRIBUTIONS}

FM wrote the manuscript. All authors were designing the concept and structure of the paper and review the final manuscript.

\section{FUNDING}

This work was supported by the Spanish Ministry of Science Grant No. PSI2015-68793-C3-1-R. brain hypometabolism in subjects with Alzheimer's disease: an Eeg-Pet study. Neurobiol. Aging 48, 122-34. doi: 10.1016/j.neurobiolaging.2016.08.021

Babiloni, C., Del Percio, C., Lizio, R., Marzano, N., Infarinato, F., Soricelli, A., et al. (2014). Cortical sources of resting state electroencephalographic alpha rhythms deteriorate across time in subjects with amnesic mild cognitive impairment. Neurobiol. Aging 35, 130-42. doi: 10.1016/j.neurobiolaging.2013. 06.019

Babiloni, C., Del Percio, C., Lizio, R., Noce, G., Lopez, S., Soricelli, A., et al. (2018). Functional cortical source connectivity of resting state electroencephalographic alpha rhythms shows similar abnormalities in patients with mild cognitive impairment due to Alzheimer's and Parkinson's diseases. Clin. Neurophysiol. 129, 766-782. doi: 10.1016/j.clinph.2018.01.009 
Babiloni, C., Del Percio, C., Lizio, R., Noce, G., Lopez, S., Soricelli, A., et al. (2018). Functional cortical source connectivity of resting state electroencephalographic alpha rhythms shows similar abnormalities in patients with mild cognitive impairment due to Alzheimer's and Parkinson's diseases. Clin. Neurophysiol. 129, 766-82. doi: 10.1016/J.CLINPH.2018. 01.009

Bajo, R., Castellanos, N. P., Cuesta, P., Aurtenetxe, S., Garcia-Prieto, J., Gil-Gregorio, P., et al. (2012). Differential patterns of connectivity in progressive mild cognitive impairment. Brain Connect. 2, 21-4. doi: 10.1089/brain.2011.0069

Bajo, R., Maestú, F., Nevado, A., Sancho, M., Gutiérrez, R., Campo, P., et al. (2010). Functional connectivity in mild cognitive impairment during a memory task: implications for the disconnection hypothesis. J. Alzheimers Dis. 22, 183-93. doi: 10.3233/JAD-2010-100177

Bruña, R., Poza, J., Gómez, C., Fernández, A., and Hornero, R. (2012). Analysis of spontaneous MEG activity in mild cognitive impairment using spectral entropies and disequilibrium measures. J. Neural Eng. 9:036007. doi: 10.1088/1741-2560/9/3/036007

Buldú, J. M., Bajo, R., Maestú, F., Castellanos, N., Leyva, I., Gil, P., et al. (2011). Reorganization of functional networks in mild cognitive impairment. PLoS ONE 6:e19584. doi: 10.1371/journal.pone.0019584

Bullmore, E. T., and Bassett, D. S. (2011). Brain graphs: graphical models of the human brain connectome. Annu. Rev. Clin. Psychol. 7, 113-40. doi: 10.1146/annurev-clinpsy-040510-143934

Busche, M. A., and Konnerth, A. (2016). Impairments of neural circuit function in Alzheimer's disease. Philos. Trans. R. Soc. London. Ser. B Biol. Sci. 371, 1-10. doi: 10.1098/rstb.2015.0429

Canuet, L., Pusil, S., López ME, Bajo, R., Pineda-Pardo JÁ, Cuesta, P., et al. (2015). Network disruption and cerebrospinal fluid amyloid-beta and phospho-tau levels in mild cognitive impairment. J. Neurosci. 35, 10325-30. doi: 10.1523/JNEUROSCI.0704-15.2015

Crossley, N. A., Mechelli, A., Scott, J., Carletti, F., Fox, P. T., Mcguire, P., et al. (2014). The hubs of the human connectome are generally implicated in the anatomy of brain disorders. Brain 137, 2382-95. doi: 10.1093/brain/a wu132

Cuesta, P., Garcés, P., Castellanos NP, López ME, Aurtenetxe, S., Bajo, R., et al. (2015). Influence of the APOE $\varepsilon 4$ allele and mild cognitive impairment diagnosis in the disruption of the MEG resting state functional connectivity in sources space. J. Alzheimers Dis. 44, 493-505. doi: 10.3233/JAD-1 41872

Dauwan, M., van Dellen, E., van Boxtel, L., van Straaten, E. C. W., de Waal, H., Lemstra, A. W., et al. (2016). EEG-directed connectivity from posterior brain regions is decreased in dementia with Lewy bodies: a comparison with Alzheimer's disease and controls. Neurobiol. Aging 41, 122-9. doi: 10.1016/j.neurobiolaging.2016.02.017

Delbeuck, X., Van der Linden, M., and Collette, F. (2003). Alzheimer's disease as a disconnection syndrome? Neuropsychol. Rev. 13, 79-92. doi: 10.1023/A:1023832305702

Delli Pizzi, S., Punzi, M., Sensi, S. L., and Alzheimer's Disease Neuroimaging Initiative. (2019). Functional signature of conversion of patients with mild cognitive impairment. Neurobiol. Aging 74, 21-37. doi: 10.1016/j.neurobiolaging.2018.10.004

Drzezga, A., Becker, J. A., Van Dijk, K. R., Sreenivasan, A., Talukdar, T., Sullivan, C., et al. (2011). Neuronal dysfunction and disconnection of cortical hubs in non-demented subjects with elevated amyloid burden. Brain 134, 1635-46. doi: 10.1093/brain/awr066

Dubois, B., Epelbaum, S., Nyasse, F., Bakardjian, H., Gagliardi, G., Uspenskaya, O., et al. (2018). Cognitive and neuroimaging features and brain $\beta$ amyloidosis in individuals at risk of Alzheimer's disease (INSIGHTpreAD): a longitudinal observational study. Lancet Neurol. 17, 335-46. doi: $10.1016 /$ S1474-4422(18)30029-2

Dubois, B., Hampel, H., Feldman, H. H., Scheltens, P., Aisen, P., Andrieu, S., et al. (2016). Preclinical Alzheimer's disease: definition, natural history, and diagnostic criteria. Alzheimers Dement. 12, 292-323. doi: 10.1016/j.jalz.2016.02.002

Fernández, A., Hornero, R., Gómez, C., Turrero, A., Gil-Gregorio, P., MatíasSantos, J., et al. (2010). Complexity analysis of spontaneous brain activity in Alzheimer disease and mild cognitive impairment: an MEG study.
Alzheimer Dis. Assoc. Disord. 24, 182-9. doi: 10.1097/WAD.0b013e3181c $727 \mathrm{f} 7$

Fernández, A., Maestú, F., Amo, C., Gil, P., Fehr, T., Wienbruch, C., et al. (2002). Focal temporoparietal slow activity in Alzheimer's disease revealed by magnetoencephalography. Biol. Psychiatry 52, 764-70. doi: 10.1016/S0006-3223(02)01366-5

Fernández, A., Zuluaga, P., Abásolo, D., Gómez, C., Serra, A., Méndez, M. A., et al. (2012). Brain oscillatory complexity across the life span. Clin. Neurophysiol. 123, 2154-62. doi: 10.1016/j.clinph.2012.04.025

Fonseca, L. C., Tedrus, G. M., Carvas, P. N., and Machado, E. C. (2013). Comparison of quantitative EEG between patients with Alzheimer's disease and those with Parkinson's disease dementia. Clin. Neurophysiol. 124, 1970-4. doi: 10.1016/j.clinph.2013.05.001

Fornito, A., Zalesky, A., and Breakspear, M. (2015). The connectomics of brain disorders. Nat. Rev. Neurosci. 16, 159-72. doi: 10.1038/nr n3901

Garcés, P., Martin-Buro, M. C., and Maestu, F. (2016a). Quantifying the testretest reliability of MEG resting state functional connectivity. Brain Connect. 6, 448-60. doi: 10.1089/brain.2015.0416

Garcés, P., Pereda, E., Hernández-Tamames, J. A., Del-Pozo, F., Maestú, F., PinedaPardo, J. Á., et al. (2016b). Multimodal description of whole brain connectivity: a comparison of resting state MEG, fMRI, and DWI. Hum. Brain Mapp. 37, 20-34. doi: 10.1002/hbm.22995

Garcés, P., Vicente, R., Wibral, M., Pineda-Pardo, J. Á., López, M. E., Aurtenetxe, S., et al. (2013). Brain-wide slowing of spontaneous alpha rhythms in mild cognitive impairment. Front. Aging Neurosci. 5:100. doi: 10.3389/fnagi.2013.00100

Garcia-Marin, V., Blazquez-Llorca, L., Rodriguez, J.-R., Boluda, S., Muntane, G., Ferrer, I., et al. (2009). Diminished perisomatic GABAergic terminals on cortical neurons adjacent to amyloid plaques. Front. Neuroanat. 3:28. doi: 10.3389/neuro.05.028.2009

Gonzalez-Escamilla, G., Atienza, M., and Cantero, J. L. (2014). Impaired cortical oscillatory coupling in mild cognitive impairment: anatomical substrate and ApoE4 effects. Brain Struct. Funct. 220, 1721-37. doi: 10.1007/s00429-014-0757-1

Gouw, A. A., Alsema, A. M., Tijms, B. M., Borta, A., Scheltens, P., Stam, C. J., et al. (2017). EEG spectral analysis as a putative early prognostic biomarker in nondemented, amyloid positive subjects. Neurobiol. Aging 57, 133-42. doi: 10.1016/j.neurobiolaging.2017.05.017

Hardy, J., and Selkoe, D. J. (2002). The amyloid hypothesis of Alzheimer's disease: progress and problems on the road to therapeutics. Science 297, 353-6. doi: $10.1126 /$ science.1072994.

Hari, R., and Puce, A. (2017). MEG-EEG Primer. New York, NY: Oxford University Press. doi: 10.1093/med/9780190497774.001.0001

Hata, M., Tanaka, T., Kazui, H., Ishii, R., Canuet, L., Pascual-Marqui, R. D., et al. (2017). Cerebrospinal fluid biomarkers of Alzheimer's disease correlate with electroencephalography parameters assessed by Exact Low-Resolution Electromagnetic Tomography (eLORETA). Clin. EEG Neurosci. 48, 338-47. doi: $10.1177 / 1550059416662119$

Hunold, A., Funke, M. E., Eichardt, R., Stenroos, M., and Haueisen, J. (2016). EEG and MEG: sensitivity to epileptic spike activity as function of source orientation and depth. Physiol. Meas. 37, 1146-62. doi: 10.1088/0967-3334/37/7 $/ 1146$

Jack, C. R., Knopman, D. S., Jagust, W. J., Petersen, R. C., Weiner, M. W., Aisen, P. S., et al. (2013). Tracking pathophysiological processes in Alzheimer's disease: an updated hypothetical model of dynamic biomarkers. Lancet Neurol. 12, 207-16. doi: 10.1016/S1474-4422(12)70291-0

Jack, C. R., Wiste, H. J., Weigand, S. D., Therneau, T. M., Knopman, D. S., Lowe, V., et al. (2017). Age-specific and sex-specific prevalence of cerebral $\beta$-amyloidosis, tauopathy, and neurodegeneration in cognitively unimpaired individuals aged 50-95 years: a cross-sectional study. Lancet Neurol. 16, 435-44. doi: 10.1016/S1474-4422(17)30077-7

Jansen, W. J., Ossenkoppele, R., Knol, D. L., Tijms, B. M., Scheltens, P., Verhey, F. R., et al. (2015). Prevalence of cerebral amyloid pathology in persons without dementia: a meta-analysis. JAMA 313, 1924-38. doi: 10.1001/jama.2015 .4668

Jelic, V., Blomberg, M., Dierks, T., Basun, H., Shigeta, M., Julin, P., et al. (1998). EEG slowing and cerebrospinal fluid tau levels in patients with 
cognitive decline. Neuroreport 9, 157-60. doi: 10.1097/00001756-19980105000032

Jelic, V., Johansson, S. E., Almkvist, O., Shigeta, M., Julin, P., Nordberg, A., et al. (2000). Quantitative electroencephalography in mild cognitive impairment: longitudinal changes and possible prediction of Alzheimer's disease. Neurobiol. Aging 21, 533-40. doi: 10.1016/S0197-4580(00)00153-6

Jelic, V., Julin, P., Shigeta, M., Nordberg, A., Lannfelt, L., Winblad, B., et al. (1997). Apolipoprotein E epsilon 4 allele decreases functional connectivity in Alzheimer's disease as measured by EEG coherence. J. Neurol. Neurosurg. Psychiatr. 63, 59-65.

Jeong, J. (2004). EEG dynamics in patients with Alzheimer's disease. Clin. Neurophysiol. 115, 1490-505. doi: 10.1016/j.clinph.2004.01.001

Jones, D. T., Knopman, D. S., Gunter, J. L., Graff-Radford, J., Vemuri, P., Boeve, B. F., et al. (2015). Cascading network failure across the Alzheimer's disease spectrum. Brain 139, 547-62. doi: 10.1093/brain/awv338

Jovicich, J., Babiloni, C., Ferrari, C., Marizzoni, M., Moretti, D. V., Del Percio, C., et al. (2018). Two-year longitudinal monitoring of amnestic mild cognitive impairment patients with prodromal Alzheimer's disease using topographical biomarkers derived from functional magnetic resonance imaging and electroencephalographic activity. J. Alzheimers Dis. doi: 10.3233/JAD-180158. [Epub ahead of print].

Koenig, T., Prichep, L., Dierks, T., Hubl, D., Wahlund, L. O., John, E. R., et al. (2005). Decreased EEG synchronization in Alzheimer's disease and mild cognitive impairment. Neurobiol. Aging 26, 165-71. doi: 10.1016/j.neurobiolaging.2004.03.008.

Kramberger, M. G., Kåreholt, I., Andersson, T., Winblad, B., Eriksdotter, M., and Jelic, V. (2013). Association between EEG abnormalities and csf biomarkers in a memory clinic cohort. Dement. Geriatr. Cogn. Disord. 36, 319-28. doi: $10.1159 / 000351677$

Kuczynski, B., Targan, E., Madison, C., Weiner, M., Zhang, Y., Reed, B., et al. (2010). White matter integrity and cortical metabolic associations in aging and dementia. Alzheimers Dement. 6, 54-62. doi: 10.1016/j.jalz.2009.04.1228

Lim, H. K., Nebes, R., Snitz, B., Cohen, A., Mathis, C., Price, J., et al. (2014). Regional amyloid burden and intrinsic connectivity networks in cognitively normal elderly subjects. Brain 137, 3327-38. doi: 10.1093/brain/awu271

López, M. E., Bruña, R., Aurtenetxe, S., Pineda-Pardo, J. Á., Marcos, A., Arrazola, J., et al. (2014). Alpha-band hypersynchronization in progressive mild cognitive impairment: a magnetoencephalography study. J. Neurosci. 34, 14551-9. doi: 10.1523/JNEUROSCI.0964-14.2014

López-Sanz, D., Bruña, R., Garcés, P., Camara, C., Serrano, N., RodríguezRojo, I. C., et al. (2016). Alpha band disruption in the AD-continuum starts in the Subjective Cognitive Decline stage: a MEG study. Sci. Rep. 6:37685. doi: $10.1038 /$ srep37685

López-Sanz, D., Bruña, R., Garcés, P., Martín-Buro, M. C., Walter, S., Delgado, M. L., et al. (2017a). Functional connectivity disruption in subjective cognitive decline and mild cognitive impairment: a common pattern of alterations. Front. Aging Neurosci. 9:109. doi: 10.3389/fnagi.2017.00109

López-Sanz, D., Garcés, P., Álvarez, B., Delgado-Losada, M. L., López-Higes, R., and Maestú, F. (2017b). Network disruption in the preclinical stages of Alzheimer's disease: from subjective cognitive decline to mild cognitive impairment. Int. J. Neural Syst. 27:1750041. doi: 10.1142/S0129065717500411

Luckhaus, C., Grass-Kapanke, B., Blaeser, I., Ihl, R., Supprian, T., Winterer, G., et al. (2008). Quantitative EEG in progressing $v s$ stable mild cognitive impairment (MCI): results of a 1-year follow-up study. Int. J. Geriatr. Psychiatry 23, 1148-55. doi: 10.1002/gps.2042

Maestú, F., Campo, P., Del Río, D., Moratti, S., Gil-Gregorio, P., Fernández, A., et al. (2008). Increased biomagnetic activity in the ventral pathway in mild cognitive impairment. Clin. Neurophysiol. 119, 1320-7. doi: 10.1016/j.clinph.2008.01.105

Maestú, F., Peña, J.-M., Garcés, P., González, S., Bajo, R., Bagic, A., et al. (2015). A multicenter study of the early detection of synaptic dysfunction in Mild Cognitive Impairment using magnetoencephalography-derived functional connectivity. NeuroImage Clin. 9, 103-9. doi: 10.1016/j.nicl.2015. 07.011

Moretti, D. V., Frisoni, G. B., Fracassi, C., Pievani, M., Geroldi, C., Binetti, G., et al. (2011). MCI patients' EEGs show group differences between those who progress and those who do not progress to AD. Neurobiol. Aging 32, 563-71. doi: 10.1016/j.neurobiolaging.2009.04.003
Moretti, D. V., Pievani, M., Pini, L., Guerra, U. P., Paghera, B., and Frisoni, G. B. (2017). Cerebral PET glucose hypometabolism in subjects with mild cognitive impairment and higher EEG high-alpha/low-alpha frequency power ratio. Neurobiol. Aging 58, 213-24. doi: 10.1016/j.neurobiolaging.2017.06.009

Nakamura, A., Cuesta, P., Fernández, A., Arahata, Y., Iwata, K., Kuratsubo, I., et al. (2018). Electromagnetic signatures of the preclinical and prodromal stages of Alzheimer's disease. Brain 141, 1470-85. doi: 10.1093/brain/awy044

Nakamura, A., Cuesta, P., Kato, T., Arahata, Y., Iwata, K., Yamagishi, M., et al. (2017). Early functional network alterations in asymptomatic elders at risk for Alzheimer's disease. Sci. Rep. 7:6517. doi: 10.1038/s41598-017-06 876-8

Nelson, P. T., Alafuzoff, I., Bigio, E. H., Bouras, C., Braak, H., Cairns, N. J., et al. (2012). Correlation of Alzheimer disease neuropathologic changes with cognitive status: a review of the literature. J. Neuropathol. Exp. Neurol. 71, 362-81. doi: 10.1097/NEN.0b013e31825018f7

Pineda-Pardo, J. Á., Martínez, K., Solana, A. B., Hernández-Tamames, J. A., Colom, R., and del Pozo, F. (2014). Disparate connectivity for structural and functional networks is revealed when physical location of the connected nodes is considered. Brain Topogr. 28, 187-96. doi: 10.1007/s10548-014-0393-3

Poil, S. S., de Haan, W., van der Flier, W. M., Mansvelder, H. D., Scheltens, P., and Linkenkaer-Hansen, K. (2013). Integrative EEG biomarkers predict progression to Alzheimer's disease at the MCI stage. Front. Aging Neurosci. 5:58. doi: 10.3389/fnagi.2013.00058

Porcaro, C., Balsters, J. H., Mantini, D., Robertson, I. H., and Wenderoth, N. (2019). P3b amplitude as a signature of cognitive decline in the older population: An EEG study enhanced by Functional Source Separation. Neuroimage 184, 535-46. doi: 10.1016/j.neuroimage.2018.09.057

Pozueta, J., Lefort, R., and Shelanski, M. L. (2013). Synaptic changes in Alzheimer's disease and its models. Neuroscience 251, 51-65. doi: 10.1016/j.neuroscience.2012.05.050

Qiu, C., Kivipelto, M., and von Strauss, E. (2009). Epidemiology of Alzheimer's disease: occurrence, determinants, and strategies toward intervention. Dialogues Clin. Neurosci. 11, 111-28.

Rossini, P. M., Del Percio, C., Pasqualetti, P., Cassetta, E., Binetti, G., Dal Forno, G., et al. (2006). Conversion from mild cognitive impairment to Alzheimer's disease is predicted by sources and coherence of brain electroencephalography rhythms. Neuroscience 143, 793-803. doi: 10.1016/j.neuroscience.2006.08.049

Schultz, A. P., Chhatwal, J. P., Hedden, T., Mormino, E. C., Hanseeuw, B. J., Sepulcre, J., et al. (2017). Phases of hyper and hypo connectivity in the Default Mode and Salience networks track with amyloid and Tau in clinically normal individuals. J. Neurosci. 37, 3263-3216. doi: 10.1523/JNEUROSCI.3263-16.2017

Sepulcre, J., Sabuncu, M. R., Li, Q., El Fakhri, G., Sperling, R., and Johnson, K. A. (2017). Tau and $A \beta$ proteins distinctively associate to functional network changes in the aging brain. Alzheimers Dement. 13, 1-9. doi: 10.1016/j.jalz.2017.02.011

Smailovic, U., Koenig, T., Kåreholt, I., Andersson, T., Kramberger, M. G., Winblad, B., et al. (2018). Quantitative EEG power and synchronization correlate with Alzheimer's disease CSF biomarkers. Neurobiol. Aging 63, 88-95. doi: 10.1016/j.neurobiolaging.2017.11.005

Smits, F. M., Porcaro, C., Cottone, C., Cancelli, A., Maria Rossini, P., and Tecchio, F. (2016). Electroencephalographic fractal dimension in healthy ageing and Alzheimer's disease. PLoS ONE 11:e0149587. doi: 10.1371/journal.pone.0149587

Stam, C. J. (2010). Use of magnetoencephalography (MEG) to study functional brain networks in neurodegenerative disorders. J. Neurol. Sci. 289, 128-34. doi: 10.1016/j.jns.2009.08.028

Stam, C. J., de Haan, W., Daffertshofer, A., Jones, B. F., Manshanden, I., van Cappellen van Walsum, A. M., et al. (2009). Graph theoretical analysis of magnetoencephalographic functional connectivity in Alzheimer's disease. Brain 132, 213-24. doi: 10.1093/brain/awn262

Stomrud, E., Hansson, O., Minthon, L., Blennow, K., Rosén, I., and Londos, E. (2010). Slowing of EEG correlates with CSF biomarkers and reduced cognitive speed in elderly with normal cognition over 4 years. Neurobiol. Aging 31, 215-23. doi: 10.1016/j.neurobiolaging.2008.03.025

Taniguchi, T., Kawamata, T., Mukai, H., Hasegawa, H., Isagawa, T., Yasuda, M., et al. (2001). Phosphorylation of tau is regulated by PKN. J. Biol. Chem. 276 10025-31. doi: 10.1074/jbc.M007427200 
Teipel, S., Bakardjian, H., Gonzalez-Escamilla, G., Cavedo, E., Weschke, S., Dyrba, M., et al. (2018). No association of cortical amyloid load and EEG connectivity in older people with subjective memory complaints. NeuroImage Clin. 17, 435-43. doi: 10.1016/j.nicl.2017.10.031

Teipel, S., Grothe, M. J., Zhou, J., Sepulcre, J., Dyrba, M., Sorg, C., et al. (2016). Measuring Cortical Connectivity in Alzheimer's disease as a brain neural network pathology: toward clinical applications. J. Int. Neuropsychol. Soc. 22, 138-63. doi: 10.1017/S1355617715000995

Vecchio, F., Miraglia, F., Iberite, F., Lacidogna, G., Guglielmi, V., Marra, C., et al. (2018). Sustainable method for Alzheimer dementia prediction in mild cognitive impairment: electroencephalographic connectivity and graph theory combined with apolipoprotein E. Ann. Neurol. 84, 302-14. doi: 10.1002/ana.25289

Vos, S. J., Xiong, C., Visser, P. J., Jasielec, M. S., Hassenstab, J., Grant, E. A., et al. (2013). Preclinical Alzheimer's disease and its outcome: a longitudinal cohort study. Lancet Neurol. 12, 957-65. doi: 10.1016/S1474-4422(13) 70194-7
Wang, Z., Jackson, R. J., Hong, W., Taylor, W. M., Corbett, G. T., Moreno, A., et al. (2017). Human brain-derived $A \beta$ oligomers bind to synapses and disrupt synaptic activity in a manner that requires APP. J. Neurosci. 37, 11947-66. doi: 10.1523/JNEUROSCI.2009-17.2017

Conflict of Interest Statement: The authors declare that the research was conducted in the absence of any commercial or financial relationships that could be construed as a potential conflict of interest.

Copyright (C) 2019 Maestú, Cuesta, Hasan, Fernandéz, Funke and Schulz. This is an open-access article distributed under the terms of the Creative Commons Attribution License (CC BY). The use, distribution or reproduction in other forums is permitted, provided the original author(s) and the copyright owner(s) are credited and that the original publication in this journal is cited, in accordance with accepted academic practice. No use, distribution or reproduction is permitted which does not comply with these terms. 